\title{
Characteristic parameters of positive cloud-to-ground lightning channel
}

\author{
Ping Yuan ${ }^{1, *}$, Rongrong Chen ${ }^{1}$, Yanling Su$^{1}$, Bin Fan ${ }^{1}$ and Xuejuan Wang ${ }^{2}$ \\ ${ }^{1}$ Key Laboratory of Atomic and Molecular Physics and Functional Materials of Gan Su Province, College of \\ Physics and Electronic Engineering, Northwest Normal University, Lanzhou 730070, People's Republic of China. \\ ${ }^{2}$ School of Electronic and Information Engineering, Nanjing University Information Science and Technology, \\ Nanjing 210044, People's Republic of China. \\ *Corresponding author.e-mail: yuanp@nwnu.edu.cn,yuanping66@163.com
}

MS received 11 January 2018; revised 23 December 2018; accepted 1 April 2019; published online 17 June 2019

The high time-resolved spectra of two natural positive cloud-to-ground (CG) lightning of which one of them contains multiple return strokes have been taken by a high-speed slit-less spectrograph. On combining with the synchronous electric field change waveform, the temperature, electrical conductivity of the return stroke channel, radius of the core current channel and the peak value of current are calculated. The correlation between the peak current and the time interval of five $\mathrm{M}$ components which overlapped with the continuous current following the subsequent return stroke R1 of multiple return strokes positive CG lightning were analysed. The results show that the average temperatures of the return stroke channels for two positive CG lightning are about 28,900-29,800 K, the radius of the core current channel is about $0.36-1.01 \mathrm{~cm}$, the estimated peak currents of the return strokes are about 18.6-38.0 kA, which are all larger than the typical values of common negative CG lightning. The peak currents of the $\mathrm{M}$ components are positively correlated with the time intervals between them.

Keywords. Temperature; discharge current; M component; positive CG lightning; radius of the core current channel; conductivity.

\section{Introduction}

The large current and strong electromagnetic radiations caused by the lightning discharge are the main causes of forest fire, power transmission system damage and many other lightning disasters (Soriano et al. 2005). Positive cloud-toground (CG) lightning usually has a strong return stroke current, and is mostly followed by continuous current, which is more harmful. The powerful return stroke current heats the discharge channel to tens of thousands of degrees and forms a plasma channel. The temperature and electrical conductivity are basic parameters reflecting the physical characteristics of a lightning discharge channel (Lu et al. 1994; Li et al. 2012; Agnes et al. 2013). At present, there are few reports on the temperature and other characteristic parameters of positive CG lightning channel.

Optical and electrical observations show that most positive CG lightning usually contains only one return stroke. The probability of positive $\mathrm{CG}$ lightning with multiple return strokes is very low. From National Lightning Detection Network data, Lyons (1996) found that among 2 million positive CG lightning, only $0.04 \%$ of them contain 
the multiple return strokes, whereas about $80 \%$ of negative flashes contain two or more strokes (Rakov and Huffines 2003). Saba et al. (2010) analysed the data recorded using a high-speed camera and lightning location system, and found that $81 \%$ of 103 positive flashes have one return stroke and the 21 of them have multiple return strokes. Nag and Rakov (2012) reported that the peak current range is $20-234 \mathrm{kA}$ with a mean of $75 \mathrm{kA}$ for 48 positive lightning according to the National Lightning Detection Network data. In general, $75 \%$ positive flashes have at least one long continuous current, and its duration time is about $40 \mathrm{~ms}$, only 30\% negative flashes have continuous current (Saba et al. 2010). The temperature and electrical conductivity of the discharge channel are closely related to the spectral properties in the lightning process (Qu et al. 2011). In this paper, based on the time-resolved spectra of two positive $\mathrm{CG}$ lightning return stroke processes recorded by a slit-less high-speed spectrograph, and according to the transport theory of air plasma, the temperature and the electrical conductivity of lightning discharge channel are calculated. Combining with the synchronised electric field change data, the peak current, the radius of core current channel and the other parameters which are related to the discharge properties are obtained. Reference data are provided for further exploration of the current transfer characteristics and thermal effect of the positive $\mathrm{CG}$ lightning process.

\section{Theoretical methods}

\subsection{Channel temperatures}

Based on the spectral information to calculate the temperature of the lightning discharge plasma channel, two basic assumptions must be met:

(1) The lightning channel is optically thin for the concerned spectral line.

(2) Within the period of research time, the channel is in the local thermodynamic equilibrium (LTE).

Uman and Orville (1965); Uman (1969) have confirmed that the lightning plasma channel satisfies these two basic assumptions. Under the condition of LTE, the relationship between the transition parameters of the spectral line and the channel temperature is as follows:

$$
\ln \left(\frac{I \lambda}{g A}\right)=-\frac{1}{k T} E+c,
$$

where $\lambda$ is the wavelength, $T$ is the temperature, $c$ is a constant, $I$ is the relative intensity of the spectral lines, $E$ is the upper excitation energy, $k$ is a Boltzmann constant, $A$ is the transition probability and $g$ is the statistical weight. The value of $g A$ can be obtained from the NIST database. On fitting the straight line with $\ln (I \lambda / g A)$ as the vertical coordinate and $E$ as the abscissa, the temperature can be calculated through the slope parameter $(-1 / k T)$.

\subsection{Conductivity of the lightning discharge channel}

The conductivity of the lightning discharge channel was (Capitelli et al. 2000; Chang et al. 2010; Wang et al. 2016b)

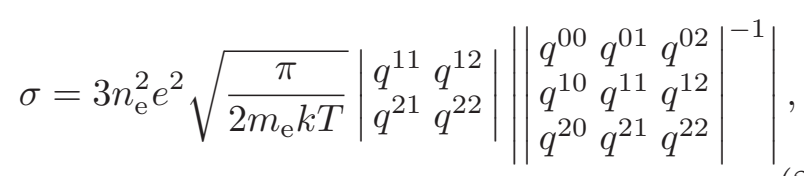

where $n_{\mathrm{e}}$ is the electron density and the $q^{\mathrm{mp}}$ (Devoto 1967) elements are co-determined by the channel electron density, the particle number density and the collision integral.

A study of the components of lightning discharge plasma shows that the concentration of ions which are more than three times the ionisation is relatively low, so the contributions of these ions to the channel characteristic parameters will be much smaller. The components in the channel mainly include: NI, NII, NIII, OI, OII, OIII, ArI, ArII, ArIII and electron. Therefore, the calculation of conductivity mainly involves the collisions between electron and electron as well as electron and the first or second ionised ions.

The collision integral between the $i$ and $j$ particles is followed as

$$
\begin{aligned}
Q_{i j}^{(\mathrm{l}, \mathrm{s})}(T)= & \frac{4(l+1)}{(s+1) !\left[2 l+1-(-1)^{1}\right]} \\
& \int_{0}^{\infty} \mathrm{e}^{-r^{2}} \gamma^{2 s+3} Q_{i j}^{(\mathrm{l})}(\xi) \mathrm{d} \gamma,
\end{aligned}
$$

where $Q_{i j}^{(\mathrm{l})}(\xi)$ is the differential transmission cross section (Liboff 1959). The reduced relative speed is defined by $\gamma=\sqrt{\left(u_{i j} / 2 \kappa T\right)} \xi$ in which $\xi$ is the relative speed of particles and $u_{i j}$ is the reduced mass of the colliding particles. 


\subsection{Radius of the core current channel}

Borovsky et al. (1995) has reported an electrodynamics model of lightning dart leaders and return strokes. In the model, both the dart leader and the return stroke are described as electromagnetic waves that propagate along a conducting lightning channel, and the electrostatic energy is stored in the leader channel. After a strong return stroke current causes the expansion and rapid heating, molecular dissociation and atomic ionisation of the channels, the stored energy is released. There are three main parts of the energy before the radial expansion of the channel (Borovsky et al. 1998):

$$
\varepsilon=\varepsilon_{\text {thermal }}+\varepsilon_{\text {ionis }}+\varepsilon_{\text {disso }},
$$

$\varepsilon_{\text {thermal }}$ is the internal energy before the channel expanded, $\varepsilon_{\text {ionis }}$ is the atomic ionisation energy and $\varepsilon_{\text {disso }}$ is the molecular dissociation energy:

$$
\begin{aligned}
\varepsilon_{\text {disso }} & =\pi r_{\text {init }}^{2} L n_{\text {molec }} \tau_{\text {disso }}, \\
\varepsilon_{\text {thermal }} & =\pi r_{\text {init }}^{2} L(1+f) \frac{3}{2} n_{\text {atomic }} \kappa T, \\
\varepsilon_{\text {ionis }} & =\pi r_{\text {init }}^{2} L n_{\text {atomic }} f \tau_{\text {ionis }},
\end{aligned}
$$

for formulas (4)-(7), where $r$ is the channel radius, $L$ is the total channel length, $T_{\text {init }}$ is the temperature before channel expansion, $f=0.97$ (Wang et al. 2010) is the ionisation degree, $\kappa=1.38 \times$ $10^{16} \mathrm{erg} / \mathrm{K}$ is Boltzmann constant, $\tau_{\text {dissio }}=9.8 \mathrm{eV}$ is the dissociation energy of $N_{2}, \tau_{\text {ionis }}=14.5 \mathrm{eV}$ is the first ionisation energy for NI, $n_{\text {molec }}$ and $n_{\text {atomic }}$ are the number density of the molecular dissociation and atomic ionisation before channel expansion, respectively, and the $n_{\text {molec }}=0.5 n_{\text {atomic }}$ (Borovsky et al. 1998).

Through the law of energy conservation, the energy (Borovsky et al. 1998) stored per unit length of the lightning channel is calculated by

$$
\frac{\varepsilon}{L}=\lambda_{\mathrm{q}}^{2}\left[\frac{1}{2}+\lg \left(\frac{E_{\text {break }}}{E_{\text {cloud }}}\right)\right] .
$$

Using equations (4)-(7) in equation (8), we get

$$
\begin{aligned}
r= & \lambda_{\mathrm{q}}\left[\frac{1}{2}+\lg \left(\frac{E_{\text {break }}}{E_{\text {cloud }}}\right)\right]^{1 / 2}\left(\pi n_{\text {atomic }}\right)^{-1 / 2} \\
& \times\left[(1+f) \frac{3}{2} \kappa T+\frac{1}{2} \tau_{\text {disso }}+f \tau_{\text {ioniz }}\right]^{-1 / 2},
\end{aligned}
$$

where $\lambda_{\mathrm{q}}$ is the channel internal charge density, $E_{\text {break }}=2.0 \times 10^{6} \mathrm{~V} / \mathrm{m}$ is the breakdown electric field value of air, the obtained value of the thunder cloud background electric field is $E_{\text {cloud }}=$ $5.0 \times 10^{4} \mathrm{~V} / \mathrm{m}$ (Borovsky et al. 1998).

According to the initial peak value of the electric field change waveform caused by the return stroke and based on the transmission line mode, the peak currents of the return stroke can be estimated.

\subsection{Estimation of the return stroke current}

Using the synchronous observation data of electric field change on the ground and corresponding theoretical models, the currents can be roughly estimated. The total electric field is given by

$$
\begin{aligned}
E_{\mathrm{z}}= & \frac{1}{4 \pi \varepsilon_{0}} \int_{-h}^{h} \frac{2\left(z-z^{\prime}\right)^{2}-r^{2}}{R^{5}} \int_{-\infty}^{t} i\left(z^{\prime}, t-R / c\right) \mathrm{d} t \\
& +\frac{2\left(z-z^{\prime}\right)^{2}-r^{2}}{c R^{4}} i\left(z^{\prime}, t-R / c\right) \\
& \left.-\frac{r^{2}}{c^{2} R^{3}} \frac{\partial i\left(z^{\prime}, t-R / c\right)}{\partial t}\right] \mathrm{d} z^{\prime}
\end{aligned}
$$

where the first three terms represent the electrostatic field, the induction electric field and the radiation electric field, respectively. When the observed distance is longer than the length of the channel, the radiation field dominates the lightning electric field, and equation (10) is written as

$$
E_{\mathrm{z}} \approx \frac{1}{2 \pi \varepsilon_{0} c^{2} r} \int_{0}^{h} \frac{\partial i\left(z^{\prime}, t-R / c\right)}{\partial t} \mathrm{~d} z^{\prime} .
$$

If the observation site is far distant from the lightning discharge channel, we have

$$
E_{\mathrm{z}}=-\frac{\nu}{2 \pi \varepsilon_{0} c^{2} r} i(0, t-r / c) .
$$

Neglect the direction of the current and only consider the magnitude of the peak value, and we can rewrite (12) as

$$
i_{\max }=\frac{2 \pi \varepsilon_{0} c^{2} s}{v} E_{\max }
$$

where $\varepsilon_{0}$ is the vacuum dielectric constant, $c$ is the speed of light, $s$ is the horizontal distance between the lightning channel and observation site, $v$ is the transmit speed of return stroke current, taking $v=$ $1.5 \times 10^{8} \mathrm{~m} / \mathrm{s}$ (Wang et al. 2016a, b). 


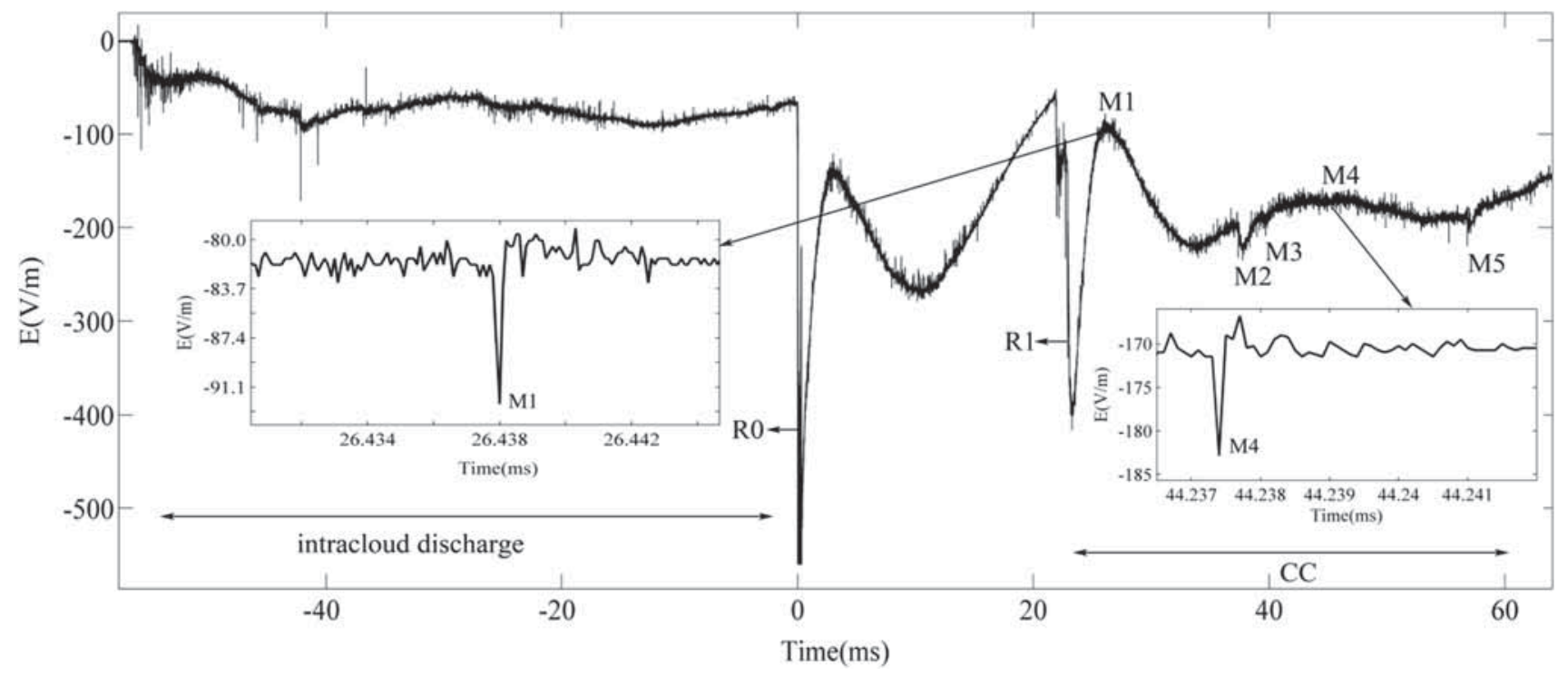

Figure 1. Electric field change caused by lightning A.

\section{Instrumentation and discussion}

\subsection{Instrumentation}

The spectra data of two CG positive lightning discharge processes were recorded by a slit-less spectrograph with a high-speed camera as the recording system, a plane transmission grating with 600 lines per millimetre was placed in front of the objective lens of the camera (Cen et al. 2014; Wang et al. 2014). The high-speed camera was set at 8000 fps with an image resolution of 1024 $\times 432$. The synchronous electric field change data were obtained by the fast antenna system and slow antenna. Its time constants are $2 \mathrm{~ms}$ and $5.6 \mathrm{~s}$ with a frequency bandwidth of $100 \mathrm{~Hz}-3.2 \mathrm{MHz}$ and 0.18 $\mathrm{Hz}-3.2 \mathrm{MHz}$, respectively. The fast and the slow antenna system synchronises with the high-speed camera system through GPS.

\subsection{Results and discussion}

The positive CG lightnings happened at the later stage of the thunderstorm process which lasted for about an hour and their occurrence times are 15:46:40 and 15:44:28, respectively. For convenience, they are named as $\mathrm{A}$ and $\mathrm{B}$, respectively. Among them, lightning $\mathrm{A}$ is a relatively rare positive CG lightning with two return stroke processes, which are named as R0 and R1, respectively, where $\mathrm{R} 0$ is the first return stroke and $\mathrm{R} 1$ represents the corresponding subsequent return stroke. Lightning $\mathrm{B}$ is a single return stroke positive $\mathrm{CG}$ discharge process. According to the arriving time differences between light and sound produced by lightning, the distances from the observation site to the two lightning discharge channels are estimated to be about 12.5 and $13.9 \mathrm{~km}$, respectively, and the altitude of the observation site is about $2560 \mathrm{~m}$.

\subsubsection{Formation process of the positive $C G$ lightning}

Figure 1 shows the electric field change caused by lightning $\mathrm{A}$. The occurrence time of the first return stroke is set as $0 \mathrm{~ms}$. It can be seen from figure 1 that there is an intracloud discharge process before R0, and a continuous current process that lasted for about $35 \mathrm{~ms}$ after R1. Brook et al. (1982) found that there is usually a continuous current process after the return stroke for the positive flash. Figure 1 also shows that the time interval between the two return strokes is about 22.9 ms. Saba et al. (2010) reported that the geometric average value of the time interval between the return strokes for positive CG lightning is $94 \mathrm{~ms}$.

Figures 2 and 3 show the luminous channel and the corresponding electric field change of intracloud discharge before the subsequent return stroke R1 for lightning A, respectively. The intracloud discharges lasted for about $0.865 \mathrm{~ms}$. As shown in figure 2(b and c), the channel initiated between the clouds, and it began going downward at about $22.678 \mathrm{~ms}$ (figure $2 \mathrm{~h}$ ). As shown in figure 3 , the electric field changes appear as an obvious unipolar 


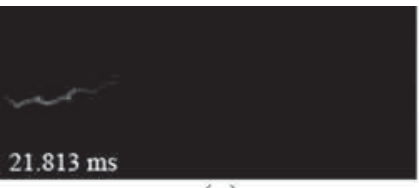

(a)

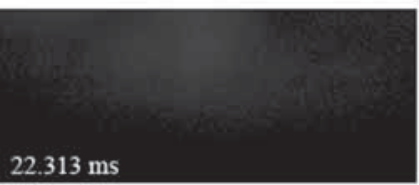

(e)

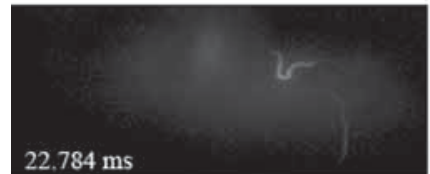

(i)

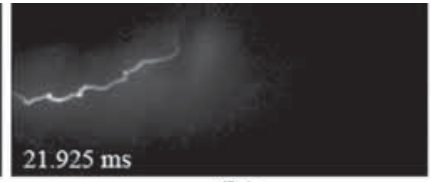

(b)

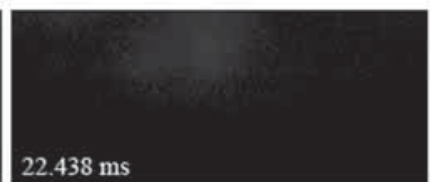

(f)

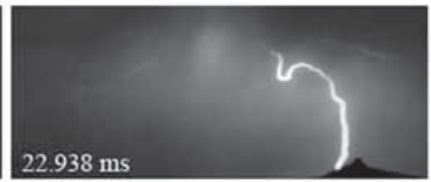

(j)

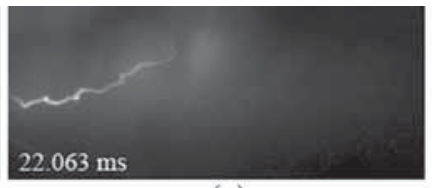

(c)

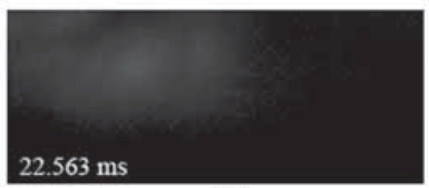

(g)

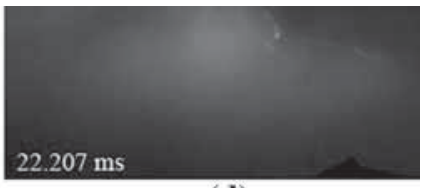

(d)

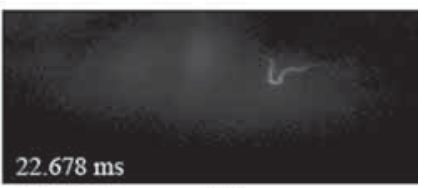

(h)

Figure 2. Luminous channel of intracloud discharge before the subsequent return stroke R1 of lightning A. (a)-(j) is arranged in chronological order of lightning development.

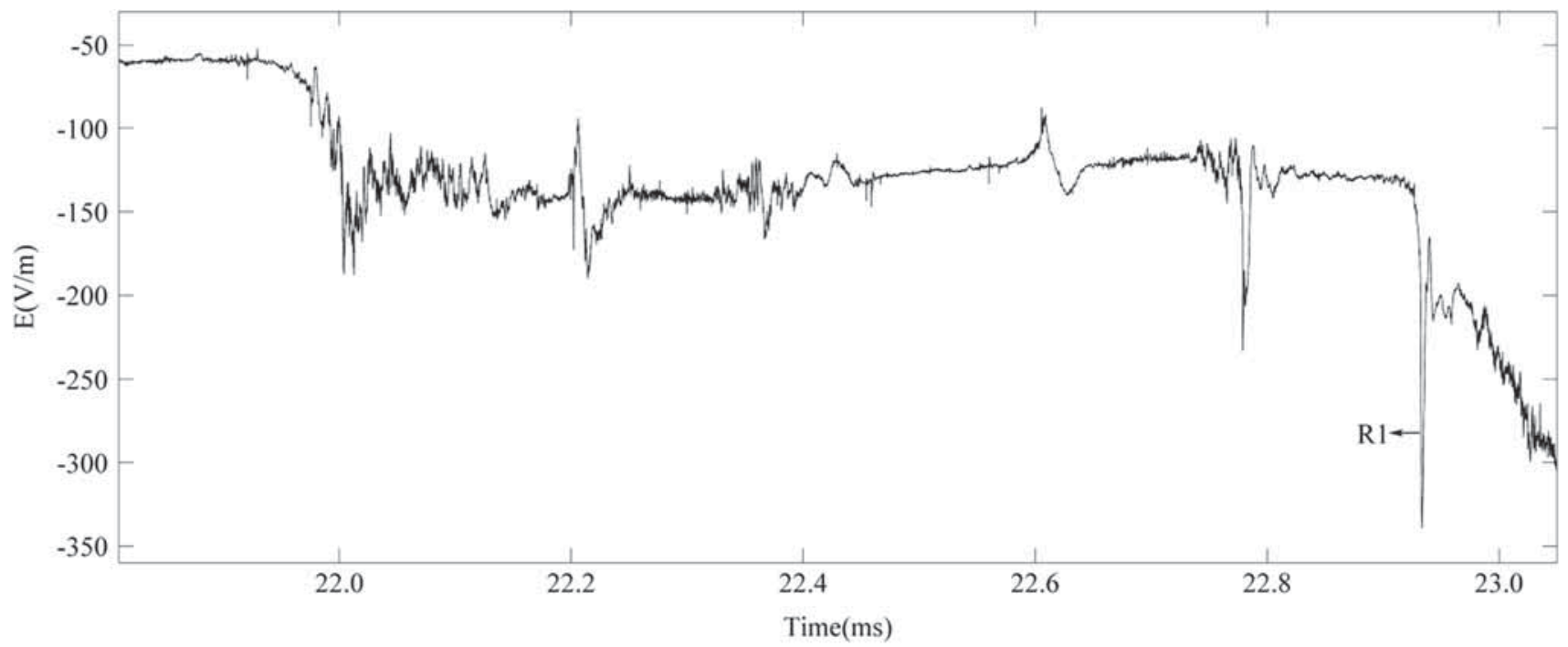

Figure 3. Electric field change of the subsequent return stroke R1 for lightning A.

pulse at $22.784 \mathrm{~ms}$. The subsequent return stroke $\mathrm{R} 1$ takes place at about $22.938 \mathrm{~ms}$ (figure 2j). According to the developing feature of the channel and the corresponding electric field changes, lightning A may be formed from a cloud branch, which accords with the conclusion reported by Thottappillil and Uman (1993).

M components are transient perturbations during the relatively steady continuing current that follows the return stroke pulse associated with channel luminosity (Rakov and Uman 2003). Based on the electric field data and optical images, the five components have been defined. Figure 4 shows the luminous channels of the subsequent return stroke R1 and five M components for lightning A, which corresponding to the electric field change waveform in figure 1. Unlike the other four M components, the luminous intensity of M5 is mainly in the horizontal channel, it should be related to the formation of lightning $\mathrm{A}$, which is initiated from a branch of intracloud discharge. Compared with the horizontal channel in figure $2 \mathrm{~b}, \mathrm{c}$ and $\mathrm{j}$, it also can be seen that the M5 should take place exactly in the same horizontal channels as the initial intracloud discharge. Table 1 shows the discharge parameters of R1 and the following $\mathrm{M}$ components for lightning A. $E$ is the initial peak value of the electric field change normalised to $100 \mathrm{~km}$. $t_{\mathrm{i}}$ is the time interval between adjacent electric field pulses and $I$ is the peak current. 


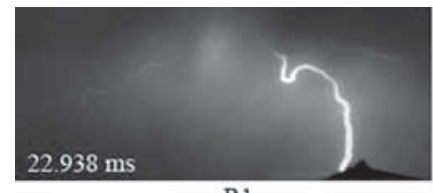

R1

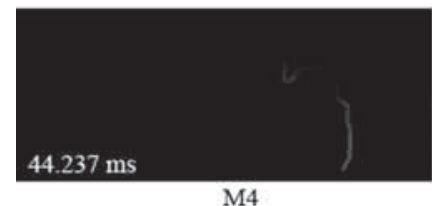

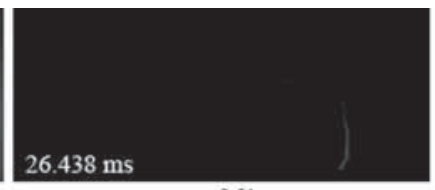

M1

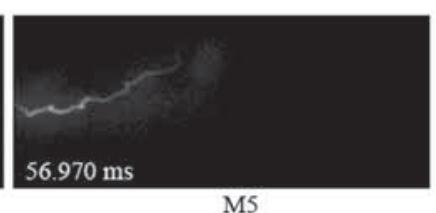

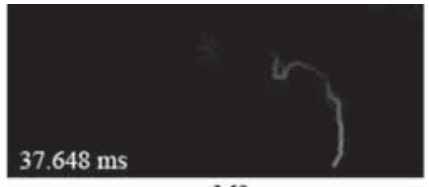

M2

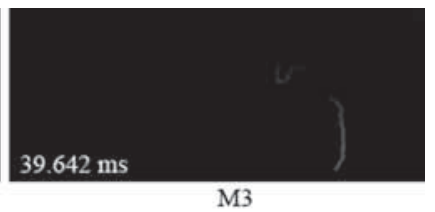

M3

Figure 4. Luminous channels of the subsequent return stroke $\mathrm{R} 1$ and the five $\mathrm{M}$ components for lightning A. The time of five $\mathrm{M}$ components is given in the graph.

Table 1. Discharge parameters of $R 1$ and $M$ components for lightning A.

\begin{tabular}{lccc}
\hline $\mathrm{A}$ & $t_{\mathrm{i}}(\mathrm{ms})$ & $E(\mathrm{~V} / \mathrm{m})$ & $I(\mathrm{kA})$ \\
\hline $\mathrm{R} 1$ & & 5.560 & 18.60 \\
$\mathrm{M} 1$ & 3.50 & 0.254 & 0.848 \\
$\mathrm{M} 2$ & 11.21 & 0.404 & 1.350 \\
$\mathrm{M} 3$ & 1.994 & 0.218 & 0.725 \\
$\mathrm{M} 4$ & 4.595 & 0.283 & 0.944 \\
$\mathrm{M} 5$ & 12.733 & 0.713 & 2.380 \\
\hline
\end{tabular}

It can be shown from table 1 that the maximum peak current of $\mathrm{M}$ components is about $2.38 \mathrm{kA}$, corresponding to the discharge of M5 in the horizontal channel. Thottappillil et al. (1995) reported that the peak current for $\mathrm{M}$ components of negative CG lightning was only a few hundred amperes. But Rakov et al. (1998b) found that the peak current of a small number of $\mathrm{M}$ components can reach several thousand amperes. The peak currents of the return stroke and $\mathrm{M}$ component for positive $\mathrm{CG}$ lightning A are all greater than the values of common negative CG lightning. Available data suggest that the $\mathrm{M}$ component peak current in positive lightning can be much higher (in the tens of kiloamperes range) than the typical values (up to a few kiloamperes) observed in negative lightning (Rakov and Uman 2003).

Figure 5 shows the relationship between the peak currents and the time interval of $\mathrm{M}$ components for positive CG lightning. It can be seen that there is a roughly positive correlation between the time interval and peak current, such as the longer the time interval between M4 and M5, the larger the peak current of M5. This characteristic is similar to the correlation between the time interval and the peak current of the return strokes (Thottappillil et al. 1992; Cooray and Pérez 1994).

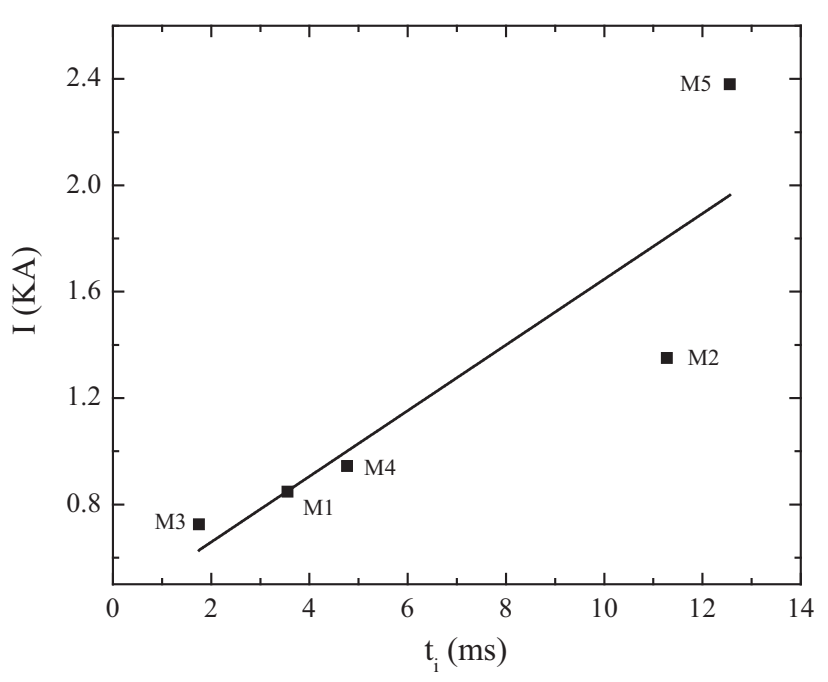

Figure 5. Relationship between the peak currents and time interval of $\mathrm{M}$ components. $\mathrm{R} 0$ indicates the first return stroke, R1 indicates the subsequent return stroke. Such as A ( R0) represents the first return stroke of lightning A.

\subsubsection{Characteristic parameters of the return stroke channel for positive CG lightning}

Spectra pictures for the whole discharge channel outside the cloud of two positive CG lightning return strokes were recorded using a high-speed camera. For quantitative analysis, some excellent positions with good spectrum resolution along the channel are selected, and the pictures are converted into spectral graphs expressed by the relative intensity of the spectral line.

Figure 6 shows the spectral graphs on one of the positions along the channel for lightning $\mathrm{A}(15: 46: 40)$ and $\mathrm{B}(15: 44: 28)$. Figure $6 \mathrm{a}$ and $\mathrm{c}$ is the spectral graphs of the first return stroke R0 for lightning $\mathrm{A}$ and $\mathrm{B}$, figure $6 \mathrm{~b}$ is the spectral graph of the subsequent return strokes R1 of lightning A. The abscissa and ordinate represent the wavelength and relative intensity of the spectral lines, 

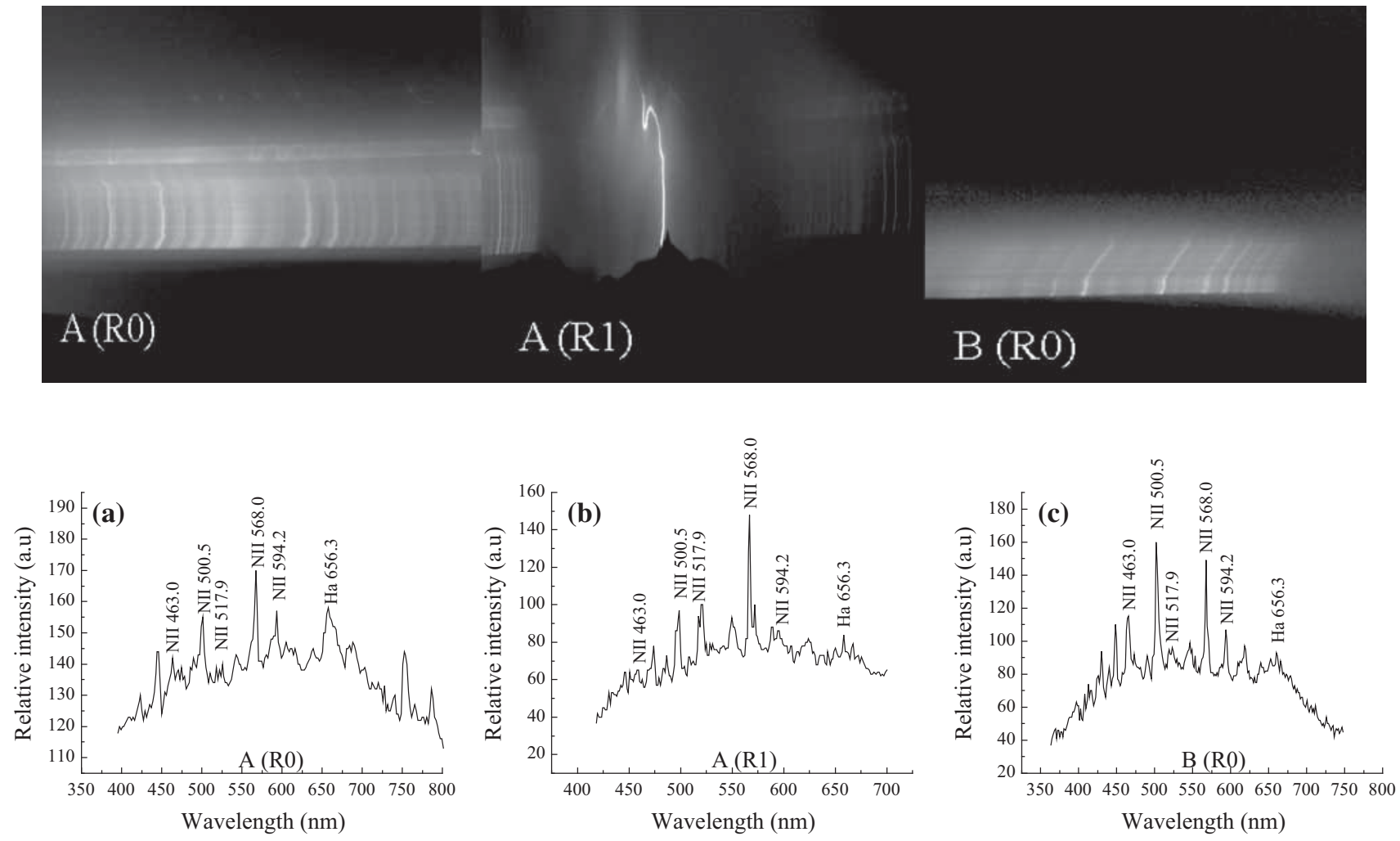

Figure 6. Original spectral images and corresponding spectral graphs of lightning A(15:46:40) and B(15:44:28). R0 indicates the first return stroke, R1 indicates the subsequent return stroke. Such as A (R0) represents the first return stroke of lightning A.

Table 2. Physical parameters of return stroke for positive lightning $A$ and $B$.

\begin{tabular}{lcccccc}
\hline $\begin{array}{l}\text { Return } \\
\text { stroke }\end{array}$ & $D(\mathrm{~km})$ & $T(\mathrm{~K})$ & $\sigma\left(10^{4} \mathrm{~S} / \mathrm{m}\right)$ & $E(\mathrm{~V} / \mathrm{m})$ & $I(\mathrm{kA})$ & $r(\mathrm{~cm})$ \\
\hline \multirow{2}{*}{ R0 } & 12.5 & 29,600 & 2.2 & 11.38 & 38.0 & 1.01 \\
$\mathrm{R} 1$ & 12.5 & 28,900 & 2.3 & 5.56 & 18.6 & 0.36 \\
& & & $\mathrm{~B}$ & & & \\
R0 & 13.9 & 29,800 & 1.9 & 8.87 & 29.6 & 0.98 \\
\hline
\end{tabular}

respectively. Like the spectrum of the negative $\mathrm{CG}$ lightning return stroke (Cen et al. 2015), the spectral lines of positive CG lightning return stroke are mainly composed of nitrogen (NII) ionic radiation in the visible range and neutral nitrogen, oxygen (NI and $\mathrm{OI}$ ) radiation in the near infrared range. The ionic lines and neutral atom lines should be radiated from the different radial positions of the channel (Wang et al. 2016a), and the NII radiations mainly from the current-carrying channel core have been analysed by Uman and Orville (1965). Because the location of the channel is not right in front of the spectrograph, the spectrum in the infrared band is outside the field of view. Figure 6 only shows the spectrum in 400-700 nm.
During practical calculation, these lines of NII with $463.0,517.9,568.0$ and $594.2 \mathrm{~nm}$ are used to calculate the temperature of the core channel by the linear fitting of (1).

Table 2 lists some physical parameters of each return strokes for two positive CG lightning. Here, $D$ is the estimated horizontal distance between the lightning channel and the observation site. Average temperatures $(T)$ and conductivity $(\sigma)$ can be obtained by using spectral information and formulas (1) and (2). $E$ is the initial peak of the corresponding electric field change of the return stroke normalised to $100 \mathrm{~km}, I$ is the peak current of the return stroke. $r$ is the radius of the core current channel. In table 2, the average 
temperature of two positive CG lightning channels is about $29,400 \mathrm{~K}$, which is slightly higher than the value of the normal negative CG lightning (Cen et al. 2015; Dong et al. 2017). The temperature of positive return strokes channel calculated by Prueitt (1963) ranges are from 24,200 to 28,400 K. The electrical conductivity is closely related to the plasma temperature. As shown in table 2, the conductivity of the return stroke channels for positive lightning $\mathrm{A}$ and $\mathrm{B}$ are in a range of $(1.9-2.3) \times 10^{4}$ $\mathrm{S} / \mathrm{m}$, which is consistent with an estimate of $10^{4}$ $\mathrm{S} / \mathrm{m}$ order of magnitude reported by Rakov (1998a) for negative lightning. The values for negative discharge channels reported by Guo et al. (2009) are in a range of $(1.62-2.27) \times 10^{4} \mathrm{~S} / \mathrm{m}$. The peak currents of the first return strokes for lightning $\mathrm{A}$ and $\mathrm{B}$ are 38.0 and $29.6 \mathrm{kA}$, respectively. The value of the subsequent return stroke for lightning $\mathrm{A}$ is $18.6 \mathrm{kA}$, which is obviously smaller than that of the first return stroke. According to USA National Lightning Location Network data, Nag and Rakov (2012) found that the peak current of positive $\mathrm{CG}$ lightning is in the range of $20-234 \mathrm{kA}$ with a geometric average of $75 \mathrm{kA}$. In one example reported by Brook et al. (1980), the average current of a positive ground flash is $70 \mathrm{kA}$. The average peak current values for negative and positive flashes were 29.90 and $63.97 \mathrm{kA}$, respectively (Sonnadara et al. 2006). The radius of the core current channel for the two positive CG lightning are in the range of $0.36-1.01 \mathrm{~cm}$, which is larger than the reported value of $0.2-1.0 \mathrm{~cm}$ for negative CG lightning (Wang et al. 2013). According to the dynamics of lightning channel corona sheath (Maslowski and Rakov 2006, 2013), lightning channel comprises a fully ionised current carrying core and an external corona sheath. The diameter of the channel core is positively proportional to the current flowing through it (Borovsky et al. 1998; Wang et al. 2014). Wang et al. (2016b) analysed multiple return strokes negative CG lightning, and found that there is a good linear relationship between the radius of the core current channel and the peak current. Roughly from table 2, such correlation should also be established for positive CG lightning.

\section{Conclusions}

According to the spectra and synchronous electric field change data, the characteristic parameters of three return strokes for two positive CG lightnings have been obtained. Their peak currents are about 18.6-38.0 kA. The average temperature, electric conductivity and radius of discharge channels are about $28,900-29,800 \mathrm{~K},(1.9-2.3) \times 10^{4} \mathrm{~S} / \mathrm{m}$ and 0.36-1.01 cm, respectively, which are all larger than the average value of the usual negative CG lightning. There is a positive correlation between the peak currents of $\mathrm{M}$ components and the time intervals between five $\mathrm{M}$ component pulses which overlapped with the continuous current.

\section{Acknowledgements}

This work was supported by the National Natural Science Foundation of China under grant Nos. 11475139, 11365019 and 11605108 and the Gansu Provincial Science and Technology Program under grant No. 1506RJZA119.

\section{References}

Agnes N, Hai-Yan T, Zuo-Qiang H, Chang-Kai S, Xun G and Jing-Quan L 2013 A comparison of single shot nanosecond and femtosecond polarison-resolved laser-induced breakdown spectroscopy of AL; Chin. Phys. B 22(1) 014209.

Borovsky Joseph E 1995 An electrodynamic description of lightning return strokes and dark leaders: Guided wave propagation along conducting cylindrical channels; $J$. Geophys. Res. 100 2697-2726.

Borovsky Joseph E 1998 Lightning energetics: Estimates of energy dissipation in channels, channel radii, and channel-heating risetimes; J. Geophys. Res. 103(D10) 11,537-11,553.

Brook M, Krehbiel P, MacLaughlan D, Takeuti T and Nakano M 1980 Positive ground stroke observations in Japanese and Florida storms; In: Proceedings in atmospheric electricity (eds) Ruhnke L $\mathrm{H}$ and Latham J, pp. 365-369.

Brook M, Nakano M, Krehbiel P and Takeuti T 1982 The electric structure of the Hokuriku winter thunderstorms; J. Geophys. Res. 87 1207-1215.

Capitelli M, Colona G and Gorse C 2000 Transport properties of high temperature air in local thermodynamic equilibrium; Eur. Phys. J. D 11 279-289.

Cen J, Yuan P and Xue S 2014 Observation of the optical and spectral characteristics of ball lightning; Phys. Rev. Lett. 112035001.

Cen J, Yuan P, Xue S and Wang X 2015 Resistance and internal electric field in cloud-to-ground lightning channel; Appl. Phys. Lett. 106054104.

Chang Z, Zhao N and Yuan P 2010 Study of the transport parameters of cloud lightning plasmas; Phys. Plasmas. 17113514

Cooray V and Pérez H 1994 Some features of lightning flashes observed in Sweden; J. Geophys. Res. 99 1068310688 . 
Devoto R S 1967 Simplified expressions for the transport properties of ionized monatomic gases; Phys. Fluids 102105

Dong X, Chen J, Wei X and Yuan P 2017 Calculating the electron temperature in the lightning channel by continuous spectrum; Plasma Sci. Technol. 19(12) 125304.

Guo Y, Yuan P, Shen X and Wang J 2009 The electrical conductivity of a cloud-to-ground lightning discharge channel; Phys. Scr. 80035901.

Li M, Wu J and Wang L 2012 Electron temperature diagnostics of aluminia plasma in a z-pinch experiment at the 'QiangGuang-1' facility; Chin. Phys. B 21(12) 322-326.

Liboff R L 1959 Transport coefficients determined using the shielded Coulomb potential; Phys. Fluids 2 40-46.

Lu T, Zhao X and Cui Z 1994 The determination of the electron temperature and electron density of laser plasma from the emission spectra; Chin. J. At. Mol. Phys. 11(2) $120-128$.

Lyons W A 1996 Sprite observations above the US high plains in relation to their parent thunderstorm systems; J. Geophys. Res. 101 29641-29652.

Maslowski G and Rakov V A 2006 A study of the lightning channel corona sheath; J. Geophys. Res. 111 D14110.

Maslowski G and Rakov V A 2013 Review of recent developments in lightning channel corona sheath research; Atmos. Res. 129-130 117-122.

Nag A and Rakov V A 2012 Positive lightning: An overview, new observations, and inferences; J. Geophys. Res. 117 D08109.

Prueitt M L 1963 The excitation temperature of lightning; J. Geophys. Res. 63 803-811.

Qu H, Yuan P and Zhang T 2011 Analysis on the correlation between temperature and discharge characteristic of cloud-to-ground lightning discharge plasma with multiple return strokes; Phys. Plasmas 18013504.

Rakov V A 1998 Some inferences on the propagation mechanisms of dart leaders and return strokes; J. Geophys. Res. 103 1879-1887.

Rakov V A and Huffines G R 2003 Return stroke multiplicity of negative cloud-to- ground lightning flashes; J. Appl. Meteorol. 42 1455-1462.

Rakov V A and Uman M A 2003 Lightning physics and effects; Cambridge University Press, New York, 687p.

Rakov V A, Uman M A, Rambo K J, Fernandez M I, Fisher R J, Schnetzer G H, Thottappillil R, Eybert-Berard A, Berlandis J P, Lalande P, Bonamy A, Laroche $\mathrm{P}$ and Bondiou-Clergerie A 1998 New insights into lightning processes gained from triggered-lightning experiments in Florida and Alabama; J. Geophys. Res. 103 14117-14130.

Saba M M F, Schulz W, Warner T A, Campos L Z S, Schumann C, Krider P E, Cummins K L and Orville R E 2010 High-speed video observations of positive lightning flashes to ground; J. Geophys. Res. 115 D24201.

Sonnadara U, Cooray V and Götschl T 2006 Characteristics of cloud-to-ground lightning flashes over Sweden; Phys. Scr. 74(5) 541-548.

Soriano L R, Pablo F D and Tomas C 2005 Ten-year study of cloud-to-ground lightning activity in the Iberian Peninsula; J. Atmos. Sol.-Terr. Phys. 67(16) 1632-1639.

Thottappillil R and Uman M A 1993 Comparison of lightning return-stroke models; J. Geophys. Res. 98 22,90322,914 .

Thottappillil R, Rakov V A, Uman M A, Beasley W H, Master M J and Shelukhin D V 1992 Lightning subsequentstroke electric field peak greater than the first stroke peak and multiple ground terminations; J. Geophys. Res. 97 7503-7509.

Thottappillil R, Goldberg J D, Rakov V A, Uman M A, Fisher R J and Schnetzer G H 1995 Properties of M components from currents measured at triggered lightning channel base; J. Geophys. Res. 100 25,711-25,720.

Uman M A 1969 Determination of lightning temperature; $J$. Geophys. Res. 74 949-957.

Uman M A and Orville R E 1965 The opacity of lightning; J. Geophys. Res. 70 5491-5497.

Wang J, Yuan P, Guo F, Qie X, Ouyang Y and Zhang Y 2010 Particle densities and distributions in cloud lightning channels; Chin. J. Geophys. 53(3) 240-246.

Wang X, Yuan P, Cen J, Zhang T, Xue S, Zhao J and Xu H 2013 Study on the radius and energy transmission properties of lightning discharge channel by the Spectra; Acta Phys. Sin. 62(10) 109201.

Wang X, Yuan P, Cen J, Liu J and Li Y 2014 The channel radius and energy of cloud- to-ground lightning discharge plasma with multiple return strokes; Phys. Plasmas 21 033503.

Wang X, Yuan P, Cen J and Xue S 2016a Correlation between the spectral features and electric field changes for natural lightning return stroke followed by continuing current with M-components; J. Geophys. Res. Atmos. 1218615.

Wang X, Yuan P, Cen J and Xue S 2016b Thermal power and heat energy of cloud-to-ground lightning process; Phys. Plasmas 23073502 